\title{
Surface Temperature Humidity Reference System Handbook
}

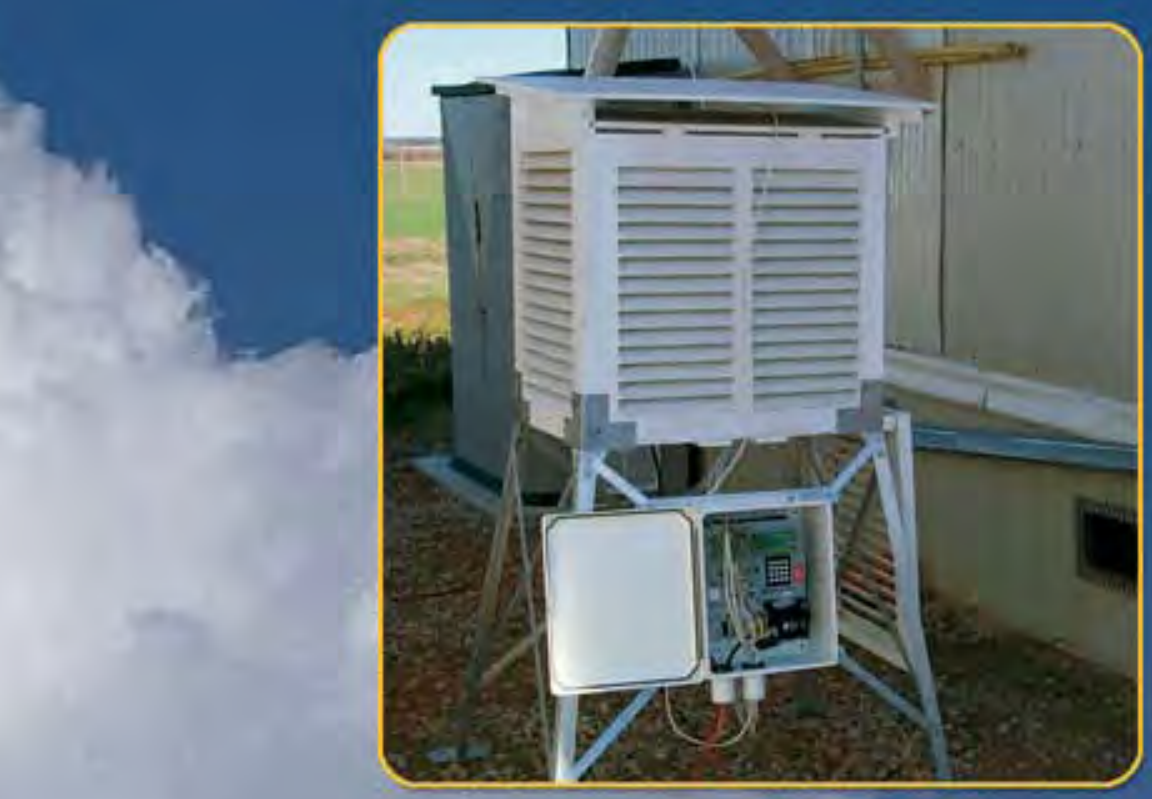

November 2005

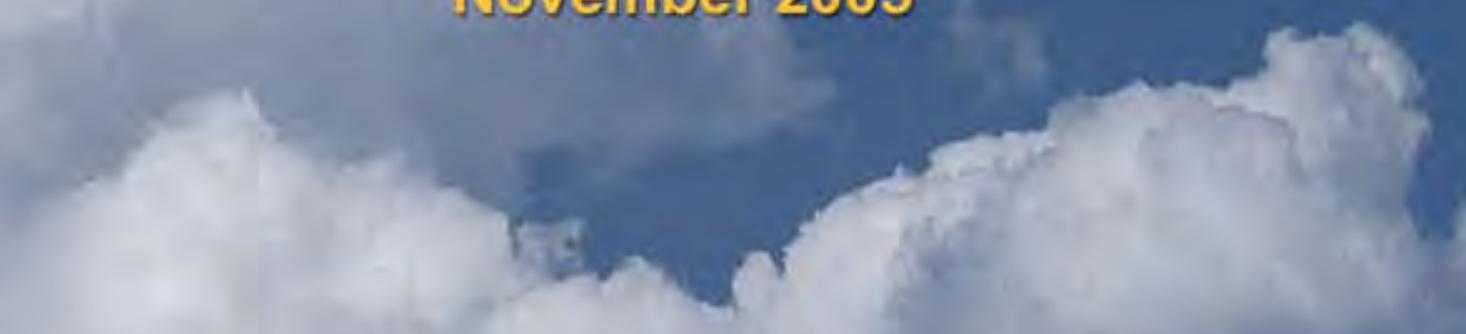




\section{Surface Temperature and Humidity Reference System (SURTHREF) Handbook}

November 2005

Work supported by the U.S. Department of Energy,

Office of Science, Office of Biological and Environmental Research 


\section{Contents}

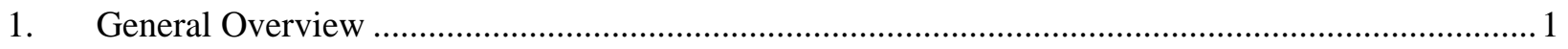

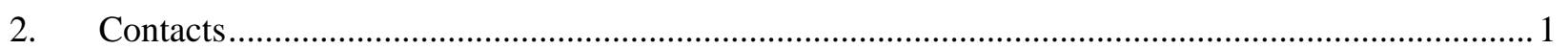

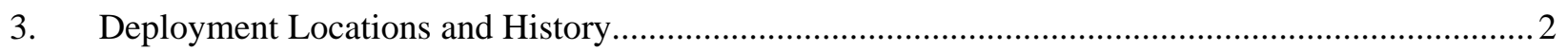

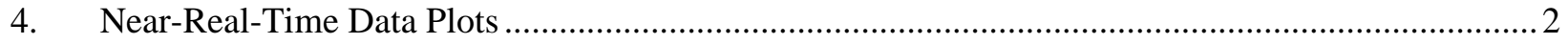

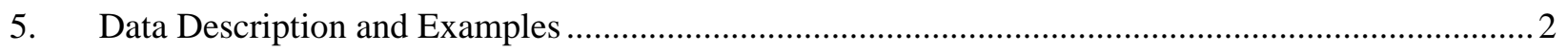

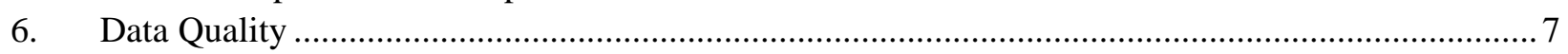

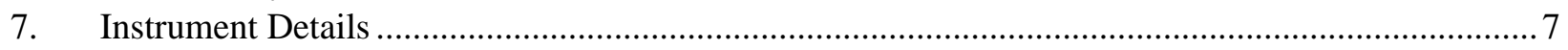

Tables

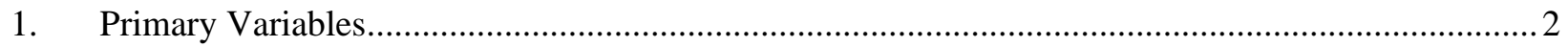

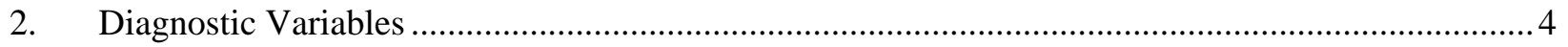

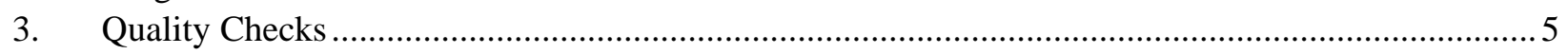

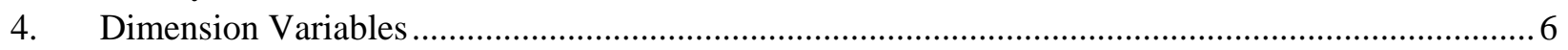




\section{General Overview}

The Surface Temperature and Humidity Reference (SURTHREF) system is intended to provide accurate reference values of ambient temperature and relative humidity for comparison with radiosonde prelaunch values.

\section{Contacts}

\subsection{Mentor}

Michael T. Ritsche

Scientific Associate

Argonne National Laboratory

Bldg. 203

Argonne, IL 60439

Phone: (630) 252-1554

Fax: (630) 252-5498

Email: mtritsche@anl.gov

Barry M. Lesht

Scientist

Argonne National Laboratory

Bldg. 203

Argonne, IL 60439

Phone: (630) 252-4208

Fax: (630) 252-5498

Email: bmlesht@anl.gov

\subsection{Instrument Developer}

\section{Data logger}

Campbell Scientific Inc.

815 W. $1800 \mathrm{~N}$.

Logan, UT 84321

Phone: (801) 753-2342

Fax: (801) 750-9540

Website: http://www.campbellsci.com

\section{Temperature/Relative Humidity Probe}

Vaisala

100 Commerce Way

Woburn, MA 01801-1068

Phone: (617) 933-4500

Fax: (617) 933-8029

Website: http://www.vaisala.com 


\section{Rotronic}

160 E. Main St

Huntingtion, NY 11743

Phone: (631) 427-3898

Fax: (631) 427-3902

Website: http://www.rotronic-usa.com/

\section{Deployment Locations and History}

The SURTHREF is located at the Southern Great Plains (SGP) site's Central Facility in Oklahoma and was installed in July 2005.

\section{Near-Real-Time Data Plots}

Near-real-time data plots can be found at the following locations:

- $\quad$ http://www.nsdl.arm.gov/Visualization/quicklook interface.shtml

- http://www.nsdl.arm.gov/Visualization/ncvweb.shtml

\section{Data Description and Examples}

\subsection{Data File Contents}

There are six temperature and relative humidity probes. Three probes (V1, V2 and V3) are from Vaisala, Inc. Three probes (R1, R2 and R3) are from Rotronic, Inc.

\subsubsection{Primary Variables and Expected Uncertainty}

Table 1. Primary Variables.

\begin{tabular}{|c|c|c|c|c||}
\hline Quantity & Variable & Unit & $\begin{array}{c}\text { Measurement } \\
\text { Interval }\end{array}$ & Resolution \\
\hline Temperature V1 Average & temp_V1_avg & C & 1 min & 0.01 \\
\hline Temperature V2 Average & temp_V2_avg & C & 1 min & 0.01 \\
\hline Temperature V3 Average & temp_V3_avg & C & 1 min & 0.01 \\
\hline Temperature R1 Average & temp_R1_avg & C & 1 min & 0.01 \\
\hline Temperature R2 Average & temp_R2_avg & C & 1 min & 0.01 \\
\hline Temperature R3 Average & temp_R3_avg & C & 1 min & 0.01 \\
\hline $\begin{array}{c}\text { Relative Humidity V1 } \\
\text { Average }\end{array}$ & RH_V1_avg & $\%$ & 1 min & 0.1 \\
\hline $\begin{array}{c}\text { Relative Humidity V2 } \\
\text { Average }\end{array}$ & RH_V2_avg & $\%$ & 1 min & 0.1 \\
\hline $\begin{array}{c}\text { Relative Humidity V3 } \\
\text { Average }\end{array}$ & RH_V3_avg & $\%$ & 1 min & 0.1 \\
\hline
\end{tabular}




\begin{tabular}{|c|c|c|c|c|}
\hline $\begin{array}{c}\text { Relative Humidity R1 } \\
\text { Averge }\end{array}$ & RH_R1_avg & $\%$ & $1 \mathrm{~min}$ & 0.1 \\
\hline $\begin{array}{c}\text { Relative Humidity R2 } \\
\text { Average }\end{array}$ & RH_R2_avg & $\%$ & $1 \mathrm{~min}$ & 0.1 \\
\hline $\begin{array}{c}\text { Relative Humidity R3 } \\
\text { Average }\end{array}$ & RH_R3_avg & $\%$ & $1 \mathrm{~min}$ & 0.1 \\
\hline Sonde Present Bit Flag & count & N/A & $1 \mathrm{~min}$ & 1 \\
\hline Temperature V1 Maximum & temp_V1_max & $\mathrm{C}$ & $1 \mathrm{~min}$ & 0.01 \\
\hline Temperature V2 Maximum & temp_V2_max & $\mathrm{C}$ & $1 \mathrm{~min}$ & 0.01 \\
\hline Temperature V3 Maximum & temp_V3_max & $\mathrm{C}$ & $1 \mathrm{~min}$ & 0.01 \\
\hline Temperature R1 Maximum & temp_R1_max & $\mathrm{C}$ & $1 \mathrm{~min}$ & 0.01 \\
\hline Temperature R2 Maximum & temp_R2_max & $\mathrm{C}$ & $1 \mathrm{~min}$ & 0.01 \\
\hline Temperature R3 Maximum & temp_R3_max & $\mathrm{C}$ & $1 \mathrm{~min}$ & 0.01 \\
\hline $\begin{array}{c}\text { Relative Humidity V1 } \\
\text { Maximum }\end{array}$ & RH_V1_max & $\%$ & $1 \mathrm{~min}$ & 0.1 \\
\hline $\begin{array}{c}\text { Relative Humidity V2 } \\
\text { Maximum }\end{array}$ & RH_V2_max & $\%$ & $1 \mathrm{~min}$ & 0.1 \\
\hline $\begin{array}{c}\text { Relative Humidity V3 } \\
\text { Maximum }\end{array}$ & RH_V3_max & $\%$ & $1 \mathrm{~min}$ & 0.1 \\
\hline $\begin{array}{l}\text { Relative Humidity R1 } \\
\text { Maximum }\end{array}$ & RH_R1_max & $\%$ & $1 \mathrm{~min}$ & 0.1 \\
\hline $\begin{array}{c}\text { Relative Humidity R2 } \\
\text { Maximum }\end{array}$ & RH_R2_max & $\%$ & $1 \mathrm{~min}$ & 0.1 \\
\hline $\begin{array}{c}\text { Relative Humidity R3 } \\
\text { Maximum }\end{array}$ & RH_R3_max & $\%$ & $1 \mathrm{~min}$ & 0.1 \\
\hline Temperature V1 Minimum & temp_V1_min & $\mathrm{C}$ & $1 \mathrm{~min}$ & 0.01 \\
\hline Temperature V2 Minimum & temp_V2_min & $\mathrm{C}$ & $1 \mathrm{~min}$ & 0.01 \\
\hline Temperature V3 Minimum & temp_V3_min & $\mathrm{C}$ & $1 \mathrm{~min}$ & 0.01 \\
\hline Temperature R1 Minimum & temp_R1_min & $\mathrm{C}$ & $1 \mathrm{~min}$ & 0.01 \\
\hline Temperature R2 Minimum & temp_R2_min & $\mathrm{C}$ & $1 \mathrm{~min}$ & 0.01 \\
\hline Temperature R3 Minimum & temp_R3_min & $\mathrm{C}$ & $1 \mathrm{~min}$ & 0.01 \\
\hline $\begin{array}{c}\text { Relative Humidity V1 } \\
\text { Minimum }\end{array}$ & RH_V1_min & $\%$ & $1 \mathrm{~min}$ & 0.1 \\
\hline $\begin{array}{c}\text { Relative Humidity V2 } \\
\text { Minimum }\end{array}$ & RH_V2_min & $\%$ & $1 \mathrm{~min}$ & 0.1 \\
\hline $\begin{array}{c}\text { Relative Humidity V3 } \\
\text { Minimum }\end{array}$ & RH_V3_min & $\%$ & $1 \mathrm{~min}$ & 0.1 \\
\hline $\begin{array}{c}\text { Relative Humidity R1 } \\
\text { Minimum }\end{array}$ & RH_R1_min & $\%$ & $1 \mathrm{~min}$ & 0.1 \\
\hline $\begin{array}{c}\text { Relative Humidity R2 } \\
\text { Minimum }\end{array}$ & RH_R2_min & $\%$ & $1 \mathrm{~min}$ & 0.1 \\
\hline $\begin{array}{c}\text { Relative Humidity R3 } \\
\text { Minimum }\end{array}$ & RH_R3_min & $\%$ & $1 \mathrm{~min}$ & 0.1 \\
\hline
\end{tabular}




\subsubsection{Definition of Uncertainty}

We define uncertainty as the range of probable maximum deviation of a measured value from the true value within a 95\% confidence interval. Given a bias (mean) error $B$ and uncorrelated random errors characterized by a variance $\sigma^{2}$, the root-mean-square error (RMSE) is defined as the vector sum of these,

$$
R M S E=\left(B^{2}+\sigma^{2}\right)^{1 / 2}
$$

( $B$ may be generalized to be the sum of the various contributors to the bias and $\sigma^{2}$ the sum of the variances of the contributors to the random errors). To determine the $95 \%$ confidence interval, we use the student's $t$ distribution: $t_{\mathrm{n} ; 0.025} \approx 2$, assuming the RMSE was computed for a reasonably large ensemble. Then the uncertainty is calculated as twice the RMSE.

\subsubsection{Secondary/Underlying Variables}

None.

\subsubsection{Diagnostic Variables}

Table 3. Diagnostic Variables.

\begin{tabular}{|c|c|c||}
\hline \multicolumn{1}{|c|}{ Quantity } & Variable & Measurement Interval \\
\hline Standard Deviation of Temperature V1 & temp_V1_std & $1 \mathrm{~min}$ \\
\hline Standard Deviation of Temperature V2 & temp_V2_std & $1 \mathrm{~min}$ \\
\hline Standard Deviation of Temperature V3 & temp_V3_std & $1 \mathrm{~min}$ \\
\hline Standard Deviation of Temperature R1 & temp_R1_std & $1 \mathrm{~min}$ \\
\hline Standard Deviation of Temperature R2 & temp_R2_std & $1 \mathrm{~min}$ \\
\hline Standard Deviation of Temperature R3 & temp_R3_std & $1 \mathrm{~min}$ \\
\hline Standard Deviation of Relative Humidity V1 & RH_V1_std & $1 \mathrm{~min}$ \\
\hline Standard Deviation of Relative Humidity V2 & RH_V2_std & $1 \mathrm{~min}$ \\
\hline Standard Deviation of Relative Humidity V3 & RH_V3_std & $1 \mathrm{~min}$ \\
\hline Standard Deviation of Relative Humidity R1 & RH_R1_std & $1 \mathrm{~min}$ \\
\hline Standard Deviation of Relative Humidity R2 & RH_R2_std & $1 \mathrm{~min}$ \\
\hline Standard Deviation of Relative Humidity R3 & RH_R3_std & $1 \mathrm{~min}$ \\
\hline Logger Panel Temperature & logger_temp & \\
\hline \hline
\end{tabular}




\subsubsection{Data Quality Flags}

Table 4. Quality Checks.

\begin{tabular}{|c|c|c|c|c|c|}
\hline Quantity & Variable & $\begin{array}{l}\text { Measurement } \\
\text { Interval }\end{array}$ & Min & Max & Delta \\
\hline Sample Time & qc_time & $1 \mathrm{~min}$ & & & \\
\hline Sonde Present Bit Flag & qC_count & $1 \mathrm{~min}$ & 0 & 60 & N/A \\
\hline Average Temperature V1 & qc_temp_V1_avg & $1 \mathrm{~min}$ & -40 & 50 & 10 \\
\hline Average Temperature V2 & qc_temp_V2_avg & $1 \mathrm{~min}$ & -40 & 50 & 10 \\
\hline Average Temperature V3 & qc_temp_V3_avg & $1 \mathrm{~min}$ & -40 & 50 & 10 \\
\hline Average Temperature R1 & qc_temp_R1_avg & $1 \mathrm{~min}$ & -40 & 50 & 10 \\
\hline Average Temperature R2 & qc_temp_R2_avg & $1 \mathrm{~min}$ & -40 & 50 & 10 \\
\hline Average Temperature R3 & qc_temp_R3_avg & $1 \mathrm{~min}$ & -40 & 50 & 10 \\
\hline Average Relative Humidity V1 & qC_RH_V1_avg & $1 \mathrm{~min}$ & -2 & 104 & 30 \\
\hline Average Relative Humidity V2 & qC_RH_V2_avg & $1 \mathrm{~min}$ & -2 & 104 & 30 \\
\hline Average Relative Humidity V3 & qC_RH_V3_avg & $1 \mathrm{~min}$ & -2 & 104 & 30 \\
\hline Average Relative Humidity R1 & qC_RH_R1_avg & $1 \mathrm{~min}$ & -2 & 104 & 30 \\
\hline Average Relative Humidity R2 & qC_RH_R2_avg & $1 \mathrm{~min}$ & -2 & 104 & 30 \\
\hline Average Relative Humidity R3 & qC_RH_R3_avg & $1 \mathrm{~min}$ & -2 & 104 & 30 \\
\hline Maximum Temperature V1 & qc_temp_V1_max & $1 \mathrm{~min}$ & -40 & 50 & 10 \\
\hline Maximum Temperature V2 & qc_temp_V2_max & $1 \mathrm{~min}$ & -40 & 50 & 10 \\
\hline Maximum Temperature V3 & qc_temp_V3_max & $1 \mathrm{~min}$ & -40 & 50 & 10 \\
\hline Maximum Temperature R1 & qc_temp_R1_max & $1 \mathrm{~min}$ & -40 & 50 & 10 \\
\hline Maximum Temperature R2 & qc_temp_R2_max & $1 \mathrm{~min}$ & -40 & 50 & 10 \\
\hline Maximum Temperature R3 & qc_temp_R3_max & $1 \mathrm{~min}$ & -40 & 50 & 10 \\
\hline Maximum Relative Humidity V1 & qc_RH_V1_max & $1 \mathrm{~min}$ & -2 & 104 & 30 \\
\hline Maximum Relative Humidity V2 & qc_RH_V2_max & $1 \mathrm{~min}$ & -2 & 104 & 30 \\
\hline Maximum Relative Humidity V3 & qc_RH_V3_max & $1 \mathrm{~min}$ & -2 & 104 & 30 \\
\hline Maximum Relative Humidity R1 & qC_RH_R1_max & $1 \mathrm{~min}$ & -2 & 104 & 30 \\
\hline Maximum Relative Humidity R2 & qc_RH_R2_max & $1 \mathrm{~min}$ & -2 & 104 & 30 \\
\hline Maximum Relative Humidty R3 & qc_RH_R3_max & $1 \mathrm{~min}$ & -2 & 104 & 30 \\
\hline Minimum Temperature V1 & qc_temp_V1_min & $1 \mathrm{~min}$ & -40 & 50 & 10 \\
\hline Minimum Temperature V2 & qc_temp_V2_min & $1 \mathrm{~min}$ & -40 & 50 & 10 \\
\hline Minimum Temperature V3 & qc_temp_V3_min & $1 \mathrm{~min}$ & -40 & 50 & 10 \\
\hline
\end{tabular}




\begin{tabular}{|l|l|c|c|c|c|}
\hline \hline Table 5. (contd) & \multicolumn{5}{l||}{} \\
\hline Minimum Temperature R1 & qc_temp_R1_min & $1 \mathrm{~min}$ & -40 & 50 & 10 \\
\hline Minimum Temperature R2 & qc_temp_R2_min & $1 \mathrm{~min}$ & -40 & 50 & 10 \\
\hline Minimum Temperature R3 & qc_temp_R3_min & $1 \mathrm{~min}$ & -40 & 50 & 10 \\
\hline Minimum Relative Humidity V1 & qc_RH_V1_min & $1 \mathrm{~min}$ & -2 & 104 & 30 \\
\hline Minimum Relative Humidity V2 & qc_RH_V2_min & $1 \mathrm{~min}$ & -2 & 104 & 30 \\
\hline Minimum Relative Humidity V3 & qc_RH_V3_min & $1 \mathrm{~min}$ & -2 & 104 & 30 \\
\hline Minimum Relative Humidity R1 & qc_RH_R1_min & $1 \mathrm{~min}$ & -2 & 104 & 30 \\
\hline Minimum Relative Humidity R2 & qc_RH_R2_min & $1 \mathrm{~min}$ & -2 & 104 & 30 \\
\hline Minimum Reltive Humidity R3 & qc_RH_R3_min & $1 \mathrm{~min}$ & -2 & 104 & 30 \\
\hline
\end{tabular}

\subsubsection{Dimension Variables}

\begin{tabular}{|l|c|c|c||}
\hline \hline \multicolumn{1}{||c|}{ Quantity 6. Dimension Variables. } & Variable & $\begin{array}{c}\text { Measurement } \\
\text { Interval }\end{array}$ & Unit \\
\hline Base time in Epoch & base_time & 5 min & $\begin{array}{c}\text { seconds since YYYY-mm-dd } \\
\text { XX:XX:XX X:XX }\end{array}$ \\
\hline Time offset from base_time & time_offset & 5 min & $\begin{array}{c}\text { seconds since YYYY-mm-dd } \\
\text { XX:XX:XX X:XX }\end{array}$ \\
\hline Time offset form midnight & time & 5 min & $\begin{array}{c}\text { seconds since YYYY-mm-dd } \\
\text { XX:XX:XX X:XX }\end{array}$ \\
\hline North latitude & lat & 5 min & degrees \\
\hline East longitude & lon & 5 min & degrees \\
\hline Altitude & alt & 5 min & meters above sea level \\
\hline
\end{tabular}

NOTE: lat/lon/alt refers to the ground where the instrument is sited and not the height of the sensor.

\subsection{Annotated Examples}

None.

\subsection{User Notes and Known Problems}

None. 


\subsection{Frequently Asked Questions}

None.

\section{Data Quality}

\subsection{Data Quality Health and Status}

Data Quality Health and Status (DQ HandS), http://dq.arm.gov.

NCVweb - for interactive data plotting using, http://dq.arm.gov/ncvweb/ncvweb.cgi.

\subsection{Data Reviews by Instrument Mentor}

None.

\subsection{Data Assessments by Site Scientist/Data Quality Office}

The ARM Data Quality Office uses the Data Quality Assessment (DQA) system to inform the ARM Site Operators, Site Scientists, and Instrument Team members of instrument and data flow problems as well as general data quality observations. The routine assessment reports are performed on the most recently collected ARM data, and used with the Data Quality Problem reports tool to initiate and track the problem resolution process. http://dq.arm.gov/weekly reports/weekly reports.html

\subsection{Value-Added Procedures and Quality Measurement Experiments}

Many of the scientific needs of the Atmospheric Radiation Measurement (ARM) Program are met through the analysis and processing of existing data products into value-added products (VAPs). Despite extensive instrumentation deployed at the ARM sites, there will always be quantities of interest that are either impractical or impossible to measure directly or routinely. Physical models using ARM instrument data as inputs are implemented as VAPs and can help fill some of the unmet measurement needs of the program. Conversely, ARM produces some VAPs not to fill unmet measurement needs, but to improve the quality of existing measurements. In addition, when more than one measurement is available, ARM also produces "best estimate” VAPs. A special class of VAP, called a Quality Measurement Experiment (QME), does not output geophysical parameters of scientific interest. Instead, a QME adds value to the input data streams by providing for continuous assessment of the quality of the input data based on internal consistency checks, comparisons between independent similar measurements, or comparisons between measurement with modeled results, and so forth. For more information, see the VAPs and QMEs web page at http://www.arm.gov/data/vaps.stm.

\section{Instrument Details}

\subsection{Detailed Description}

List of Components 


\section{Temperature and relative humidity sensors:}

- three Vaisala HMP-4D Series probes

- three Rotronic MP100H Series probes.

Data logger: Campbell Scientific Model CR23X Micrologger.

Meteorological Instrument Shelter: The shelter is a standard NWS "Stevenson screen" modified to allow for operator access on two sides. The shelter dimensions are 20 inches by 30 inches by 34 inches.

Aspirated Chamber: The chamber is fabricated from white polypropylene plastics. Its dimensions are 11 inches by 13 inches by 18 inches (volume $=1.49 \mathrm{feet}^{3}$ ). One end is open and covered with a removable plate containing a 7 inch $x 7.5$ inch access port. Two muffin fans, each rated at $115 \mathrm{cfm}$ are mounted at the far end. The fans produce an estimated face flow of $10.49 \mathrm{fps}$ or $3.2 \mathrm{~m} / \mathrm{s}$. The chamber has six sensor ports on its top surface to accommodate standard temperature and relative humidity probes.

Sonde positioning platform: A polypropylene platform is mounted approximately 1 inch above the bottom of the aspirated chamber. The platform is equipped with moveable guides for positioning radiosondes. A user-controlled switch is mounted on the side of the Aspirated Chamber to indicate when a radiosonde is placed in or removed from the chamber.

\subsubsection{System Configuration and Measurement Methods}

The SURTHREF system is intended to be used as a ground reference point for radiosonde launches. Radiosondes are placed inside the aspirator so that comparisons between the six T/RH probes and the radiosonde can be accomplished. It is possible that in the future a VAP will be created so that the radiosonde surface values can be corrected. For there to be an exact determination of when the radiosonde is inside the aspirator box a user operated switch is installed. When the operator places the radiosonde inside the aspirator box they flip the switch. The data logger program counts the number of seconds of each minute that the switch is in the "up" position. Any count greater than zero suggests that the radiosonde is in the aspirator.

The data logger measures each input once every second. The temperature and relative humidity data are averaged for each of the six probes once per minute and minimums and maximum are calculated along with a total count of how many seconds the "Radiosonde Present" switch was in the up position.

\subsubsection{Specifications}

\section{Temperature and Relative Humidity Probes:}

\section{Vaisala HMP-45D T/RH probe:}

Temperature: Precision: 0.01 C; Uncertainty: See "Data Acquisition Errors”

RH: Precision: $0.1 \% \mathrm{RH}$; Uncertainty: $+/-2.0 \% \mathrm{RH}(0 \%$ to $90 \% \mathrm{RH}),+/-3.0 \% \mathrm{RH}(90 \%$ to $100 \% \mathrm{RH})$ 


\section{Rotronic MP100H T/RH probe:}

Temperature: Precision: 0.01 C; Uncertainty: +/-0.2 C.

RH: Precision: $0.1 \%$ RH; Uncertainty: +/-1.5\%.

\section{Data Acquisition Errors}

The Campbell Scientific CR23X A/D converter accuracy is $+/-0.1 \%$ of full-scale range. The time base accuracy is $+/-1$ minute per month, or about $23 \mathrm{ppm}$. The collector computer checks the data logger clock once per day and corrects it if it is off by more than 2 seconds.

\subsection{Theory of Operation}

The SURTHREF system is a combination of three temperature and relative humidity probes from two different manufacturers for six probes. Although the primary use of the system is intended to provide accurate reference values of ambient temperature and relative humidity for comparison with radiosonde prelaunch values, the system includes a data logger to record time series of the measured variables.

\subsection{Calibration}

\subsubsection{Theory}

\subsubsection{Procedures}

See Section 7.4.1 of the SURTHREF User Manual for procedures.

\subsubsection{History}

The SURTHREF System was installed in July 2005 with recently calibrated sensors.

\subsection{Operation and Maintenance}

\subsubsection{User Manual}

See the SURTHREF User Manual.

\subsubsection{Routine and Corrective Maintenance Documentation}

This section is not applicable to this instrument.

\subsubsection{Software Documentation}

ARM netCDF file header descriptions may be found for the SURTHREF system at http://science.arm.gov/tool/dod/showdod.php?Inst=surthref. 


\subsubsection{Additional Documentation}

This section is not applicable to this instrument.

\subsection{Glossary}

Relative humidity: Percentage of saturated vapor pressure at the specified temperature.

See the ARM Glossary at http://www.arm.gov/about/glossary.stm.

\subsection{Acronyms}

AC alternating current

A/D Analog to Digital converter

BBSS balloon-borne sounding system

DQA Data Quality Assessment

NIST National Institute of Standards and Technology

QME Quality Measurement Experiment

RH Relative Humidity

RMSE root-mean-square error

SGP Southern Great Plains

T/RH temperature/relative humidity (sensor)

VAP value-added product

Also see the ARM Acronyms and Abbreviations at http://www.arm.gov/about/acronyms.stm.

\subsection{Citable References}

None. 